\title{
Requirement for testicular macrophages in Leydig cell proliferation and differentiation during prepubertal development in rats
}

\author{
F. Gaytan ${ }^{1}$, C. Bellido ${ }^{2}$, E. Aguilar ${ }^{2}$ and N. van Rooijen ${ }^{3}$ \\ Departments of ${ }^{1}$ Cell Biology and ${ }^{2}$ Physiology, University of Córdoba, 14071 Córdoba, Spain; and \\ ${ }^{3}$ Department of Cell Biology, Vrije Universiteit, Amsterdam, The Netherlands
}

\begin{abstract}
Testicular macrophages in rats were selectively depleted by an intratesticular injection of liposomes containing dichloromethylene diphosphonate into the right testis to study the possible role of these macrophages during the prepubertal development of Leydig cells. The contralateral testes were injected with $0.9 \% \mathrm{NaCl}$ and served as controls. The animals were injected with the liposomes and $\mathrm{NaCl}$ at $5,10,15,20$ or 25 days of age. In macrophagedepleted testes, Leydig cell development was inhibited in the animals injected at 5, I0 or 15 days of age. At 35 days of age, the testis was repopulated with macrophages and Leydig cells also developed. Rats treated at 20 or 25 days of age, when Leydig cells were already present in low numbers, did not show any further increases in the number of Leydig cells up to 35 days of age. To study whether the effects of gonadotrophins on Leydig cell development require the presence of macrophages, 2I-day-old rats, injected 3 days before with liposomes (right testis) and $\mathrm{NaCl}$ (left testis), were treated with 75 iu human $\mathrm{FSH} \mathrm{kg}^{-1}$ bodymass day $^{-1}, 10$ iu hCG per rat day ${ }^{-1}$, combined $\mathrm{hFSH}$ and $\mathrm{hCG}$, or vehicle (PBS with $0.5 \% \mathrm{BSA}$ ) for 6 days. Treatment with hCG induced a sevenfold increase in the number of Leydig cells in the left (macrophage-containing) testis, whereas no increase was found in the right (macrophage-depleted) testis. These results indicate that macrophages are needed for Leydig cell development and for the Leydig cell response to hCG during postnatal maturation.
\end{abstract}

\section{Introduction}

Puberty is the culmination of a series of developmental processes that occur at different levels of the hypothalamicpituitary-gonadal axis. In males, the most important event at the testicular level is the development of the androgenproducing cells, since most of the cell types in the testes and sex accessory organs are dependent on this steroid (Moradian ef al., 1987). The factors promoting Leydig cell proliferation and differentiation therefore play a central role in the pubertal development in the male.

Testicular development is under the control of pituitary hormones (Kerr and Sharpe, 1985; Teerds et al., 1989; Odell, 1990). However, it is becoming evident that hormone actions in the testes are modulated by local factors and cell-cell interactions (Skinner, 1991; Spiteri-Grech and Nieschlag, 1993). Numerous growth factors are present in the testes, and some of them, such as insulin-like growth factor I (IGF-I), transforming growth factor $\alpha$ (TGF- $\alpha$ ) and interleukin 1 (IL-I) stimulate $\left[{ }^{3} \mathrm{H}\right]$ thymidine incorporation into immature Leydig cells in vitro (Khan et al., 1992a, b; Moore and Morris, 1993). However, the relevance of these factors in vivo is not known.

Macrophages accumulate in the testes during development (Hutson, 1990). In adulthood, they constitute a numerically

Received 6 May 1994 important component of the rat testicular interstitium and are morphologically and functionally coupled to Leydig cells (Miller et al., 1983; Bergh, 1987). In addition, macrophagederived factors seem to modulate the steroidogenic activity of Leydig cells (Yee and Hutson, 1985; Xiong and Hales, 1993; Moore and Hutson, 1994; Sun and Risbridger, 1994). In a previous study (Gaytan et al., 1994a) we showed that testicular macrophages are required for Leydig cell regeneration after treatment of adult rats with the specific Leydig cell cytotoxin ethylene dimethane sulfonate (EDS).

In this study, the requirements of testicular macrophages during Leydig cell development were examined by depleting testicular macrophages by intratesticular injection of liposomes containing dichloromethylene diphosphonate $\left(\mathrm{Cl}_{2} \mathrm{MDP}-\mathrm{lp}\right)$ (Bergh et al., 1993) in prepubertal rats at different ages. In this paper, we report that macrophages are needed for Leydig cell development during postnatal testicular maturation.

\section{Materials and Methods}

\section{Animals}

Wistar male rats born in our laboratory were used. Animals were maintained under controlled light and temperature and had free access to food and water. 


\section{Chemicals and hormones}

Dichloromethylene diphosphonate $\left(\mathrm{Cl}_{2} \mathrm{MDP}\right)$ was a kind gift from Boehringer Mannheim GmbH (Mannheim). Phosphatidylcholine (Lipoid E PC) was a kind gift from Lipoid KG (Ludwigshafen). $\mathrm{Cl}_{2} \mathrm{MDP}$-containing liposomes $\left(\mathrm{Cl}_{2} \mathrm{MDP}-\mathrm{lp}\right.$ ) and PBS-containing liposomes (PBS-lp) were prepared as described by van Rooijen (1989). Human (h) FSH (Metrodin) was a kind gift of J. F. Tresguerres (Serono, Madrid). hCG (Pregnyl) was purchased from Organon (Oss).

\section{Experiment 1}

The right testes of rats were injected with $\mathrm{Cl}_{2} \mathrm{MDP}-\mathrm{lp}$ and the left testes were injected with PBS-lp or $\mathrm{NaCl}$ at 5, 10, 15, 20 or 25 days of age. The injected volumes were about $10 \%$ of the testicular volume; that is, $1,1.5,5,15$ or $20 \mu \mathrm{l}$, respectively, which corresponded to the same relative volume as that given to adult rats in studies by Bergh $e t$ al. (1993) and Gaytan $e$ al. (1994a). Animals (five per group) were killed at 35 days of age and the testes weighed and processed for histological study. To assess testicular development in normal conditions, groups of age-matched intact rats (five per group) were killed at 15, 20, 25,30 or 35 days of age and their right testes processed for histology. No significant differences were found between PBS-lp-injected and $\mathrm{NaCl}$-injected testes. Therefore, PBS-lp was not injected in subsequent experiments and data from PBS-lpinjected testes are not shown.

\section{Experiment 2}

The data from Expt $I$ indicated that by 35 days of age, macrophages had repopulated the testicular interstitium of the animals treated at 5, 10 or 15 days of age. Additional groups of animals were therefore injected as in Expt 1 at 5, 10 and 15 days of age (five animals per group) and killed 10 or 15 days after treatment. The testes were processed for histological study.

\section{Experiment 3}

To analyse whether the actions of gonadotrophins on Leydig cell development require the presence of testicular macrophages, 18-day-old rats were injected with $14 \mu \mathrm{l}$ $\mathrm{Cl}_{2} \mathrm{MDP}-\mathrm{lp} / \mathrm{NaCl}$ (right/left testes). Three days later, these

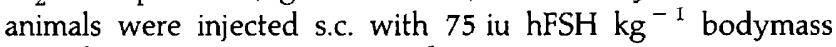
day $^{-1}, 10$ iu hCG per rat day ${ }^{-1}$, combined hCG and hFSH, or vehicle (PBS with $0.5 \%$ BSA) for 6 days. The hormone dosages were based on previous studies (Bergendahl et al., 1991). On the following day (at 27 days of age), five animals per group were killed and the testes weighed and processed for histological study.

Two days before death, animals were injected i.p. with $0.5-1.0 \mathrm{ml}$ (depending on the age) of 3\% Trypan blue in saline to label testicular macrophages. Previous studies have shown that this procedure does not modify the number of testicular macrophages and that no other testicular cell types incorporate Trypan blue (Gaytan et al., 1994a).

\section{Tissue processing}

Testes were fixed in Bouin-Hollande's fluid. Small incisions were made in the tunica albuginea to facilitate penetration of the fixative. After $12 \mathrm{~h}$, sections perpendicular to the longest axis of the organ were made and fixation was continued for an additional $24 \mathrm{~h}$. Afterwards, the testes were routinely processed for paraffin embedding. Sections were cut and stained with $1 \%$ neutral red, haematoxylin and eosin, or $1 \%$ toluidine blue.

\section{Cell counting}

Leydig cells were recognized in sections stained with neutral red or haematoxylin and eosin by their round nuclei with a characteristic punctate chromatin pattern (Hardy et al., 1989; Teerds et al., 1989). Only Leydig cells of the adult population were counted, since fetal Leydig cells represent a small proportion of the total Leydig cell counts from 15 days of age onward and constitute a static population after birth (Kerr and Knell, 1988).

Macrophages were clearly recognizable by the presence of Trypan-blue-containing cytoplasmic vacuoles. They had a round nucleus and large cytoplasm.

The numbers of Leydig cells and macrophages per testis were derived from their numerical densities $(\mathrm{Nv})$. $\mathrm{Nv}$ was obtained by a derivation of the Floderus equation, by counting the number of cells per unit area $(\mathrm{Na})$ at two different section thicknesses $t_{1}$ and $t_{2}$ ( 4 and $6 \mu \mathrm{m}$, respectively). In this way,

$$
N v=\left(N a_{2}-N a_{1}\right) /\left(t_{2}-t_{1}\right),
$$

where $N a_{1}$ and $N a_{2}$ are the number of cells per area unit at $t_{1}$ and $t_{2}$ section thickness, respectively. This method was used by Loud et al. (1978) and Bergh (1981) and its advantage is its independency of the particle size and shape. The number of cells (counted only when the nucleus was present in the section) was counted in at least 25 microscope fields $\left(0.160 \mathrm{~mm}^{2}\right.$ per field) with the $\times 40$ objective from five different sections per rat for each of the two section thicknesses. Areas in which there was artifactual tubule separation were discarded. Section thickness was determined by Small's method (Elias and Hyde, 1980). The product of $\mathrm{Nv}$ by the corresponding testicular volume (obtained by Archimedes' principle; Elias and Hyde, 1980) gives the total number of cells per testis. As the general structure of the testes was not changed after treatment, shrinkage was assumed to be equivalent in both testes, and correction factors for changes in tissue volume during processing were not applied.

\section{Statistical analyses}

Statistical analyses were performed by ANOVA and Tukey's test for multiple comparison among means, by Student's $t$ test when only two means were compared, and by Student's $t$ test for paired data for comparison between right and left organs. 

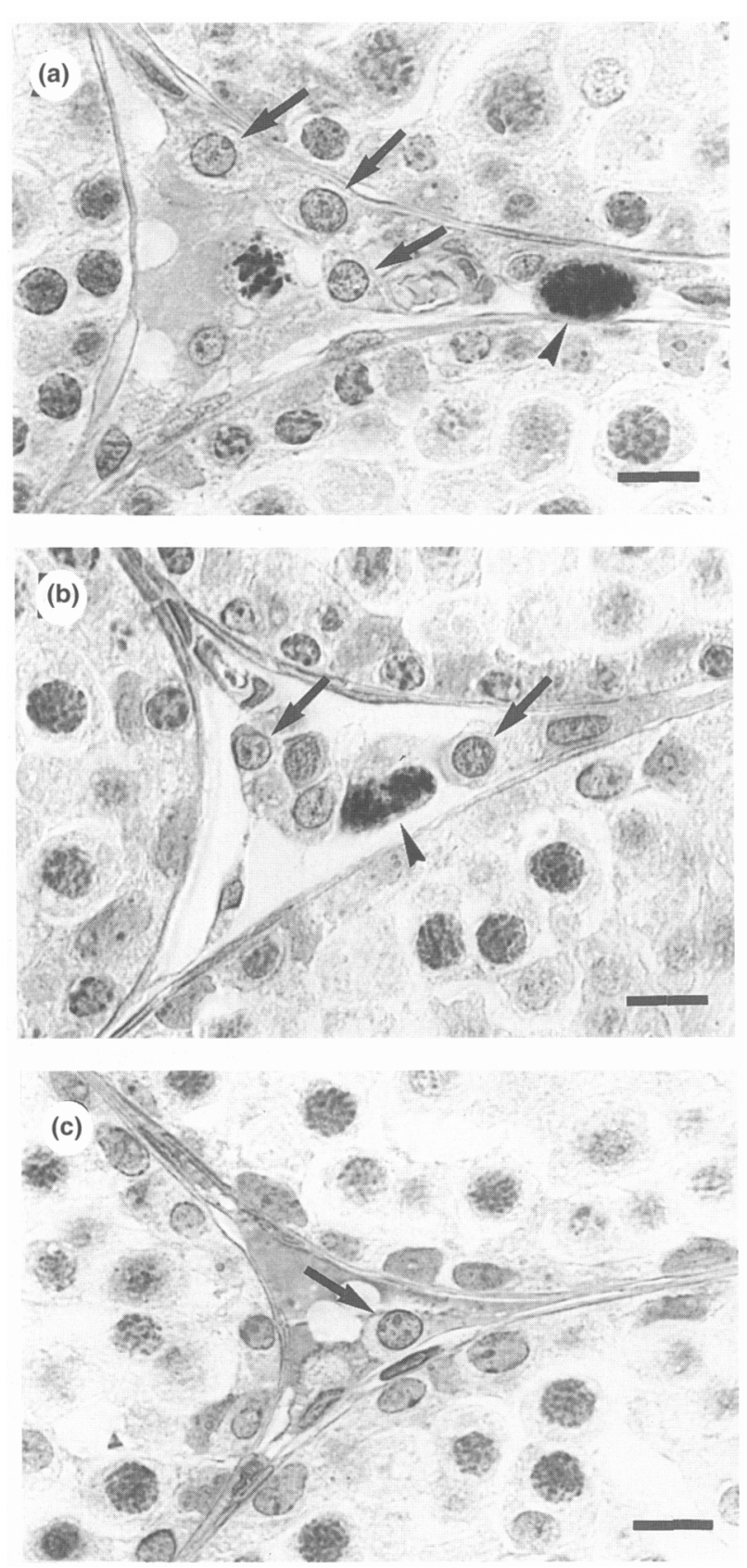

Fig. 1. Representative interstitial areas from (a) the left and (b, c) the right testes of 35-day-old rats treated with dichloromethylenediphosphonate-containing liposomes $\left(\mathrm{Cl}_{2} \mathrm{MDP}-\mathrm{lp}\right.$ ) (right testes) or $\mathrm{NaCl}$ (left testes) at (b) 5 or (c) 20 days of age. Macrophages (arrowheads) and Leydig cells (arrows) can be observed. Sections are $4 \mu \mathrm{m}$ thick and are stained with neutral red. Scale bar represents $10 \mu \mathrm{m}$.

\section{Results}

Development of Leydig cells after macrophage depletion at different ages (Expts 1 and 2)

At 35 days of age, the left $(\mathrm{NaCl}$-injected) testis of the animals treated at different ages had similar morphology; macrophages and Leydig cells were abundant (Fig. 1a). In the right $\left(\mathrm{Cl}_{2} \mathrm{MDP}\right.$-lp-injected) testis of the animals treated at 5, 10

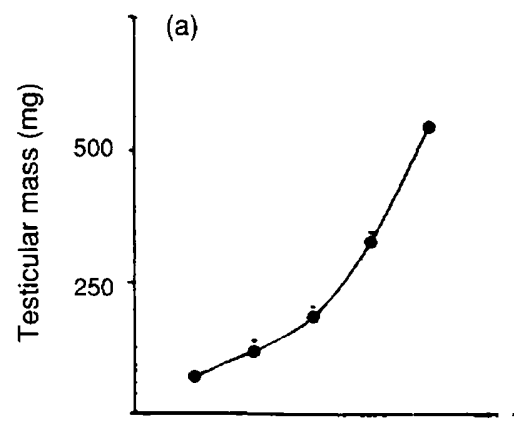

(d)
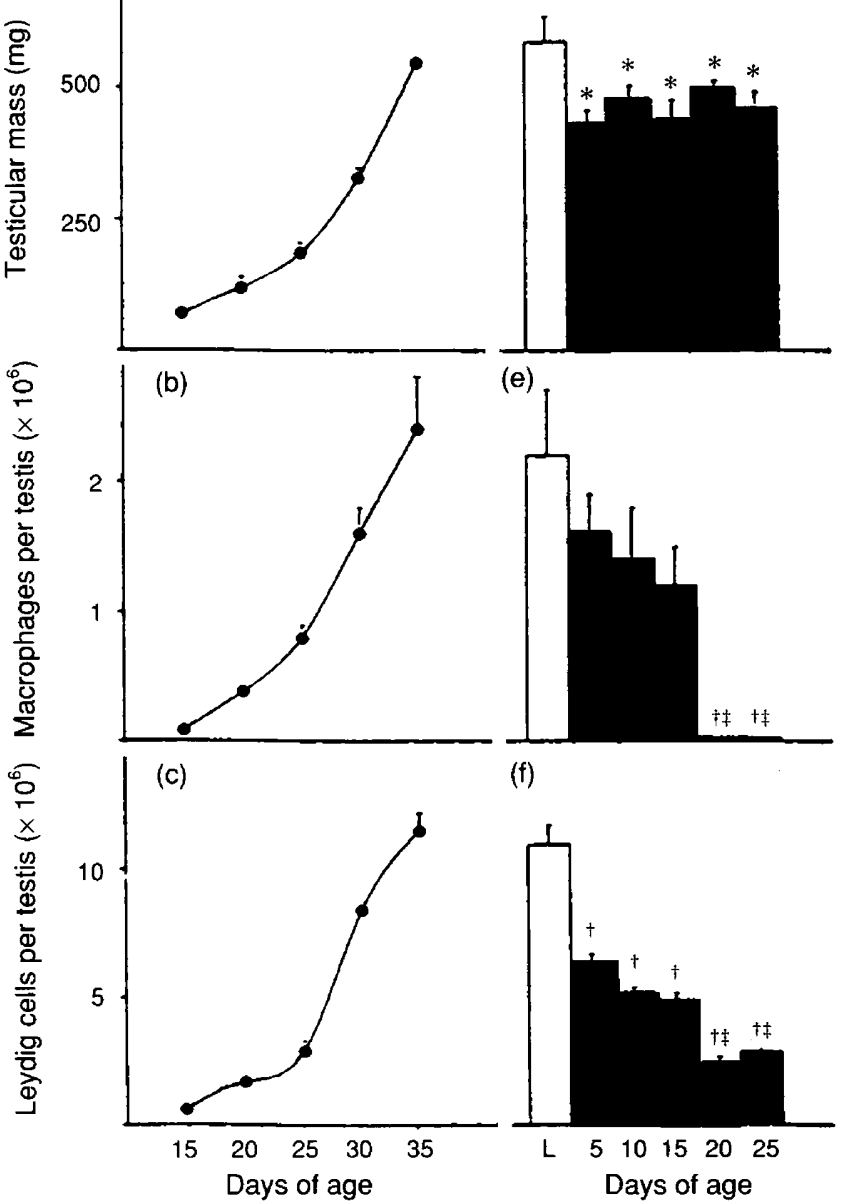

(f)

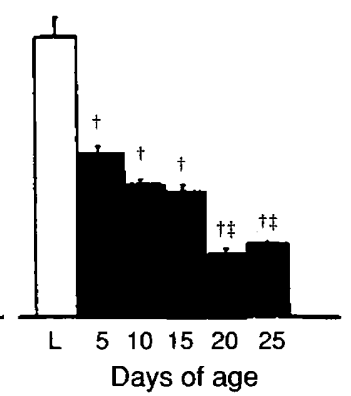

Fig. 2. Effects of testicular macrophage depletion of rats at different ages. Data from $(a, b, c)$ intact rats and (d, e, f) 35-day-old rats treated with dichloromethylene-diphosphonate-containing liposomes $\left(\mathrm{Cl}_{2}\right.$ MDP-lp; right testes) or $\mathrm{NaCl}$ (left testes). In (d, e, f) ( $\square$ ) corresponds to the left testes of rats treated at 5 days of age $(L)$, and $(\boldsymbol{D})$ to the values found for the right testes of animals injected at the ages indicated. ${ }^{*} P<0.05$, compared with left testes; ${ }^{\dagger} P<0.01$, compared with left testes; ${ }^{\ddagger} P<0.01$, compared with the right testes of animals treated on days 5,10 or 15 days of age. Data were analysed by ANOVA and Tukey's comparison.

or 15 days of age, macrophages and Leydig cells were also present (Fig. 1b). However, in the $\mathrm{Cl}_{2} \mathrm{MDP}$-lp-injected testes of animals treated at 20 or 25 days of age, macrophages were absent and Leydig cells scarce (Fig. 1c).

In intact rats, the testicular mass (Fig. 2a) and the number of macrophages (Fig. 2b) and Leydig cells (Fig. 2c) increased considerably from 15 to 35 days of age. The left testis of the animals treated with $\mathrm{NaCl}$ at different ages had similar characteristics; the values shown correspond to the mean ( \pm SEM values of the left $(\mathrm{NaCl}$-injected) testis of the animals treated at 5 days of age. These values were not significantly different from those of intact rats at the same age. The testes injected with $\mathrm{Cl}_{2} \mathrm{MDP}$-lp showed a slightly decreased $(P<0.05)$ testicular mass (Fig. 2d). Macrophages were absent in the animals injected on days 20 or 25 , whereas they were present in the right $\left(\mathrm{Cl}_{2} \mathrm{MDP}\right.$-lp-injected) testis of the animals injected at 5 , 
10 or 15 days of age (Fig. 2e). There were significantly fewer Leydig cells in the $\mathrm{Cl}_{2} \mathrm{MDP}$-lp-injected testis (by $50 \%$ on average; $P<0.01$ ) in the animals treated at $5-15$ days of age, and by $80 \%$ in those treated at 20 or 25 days of age $(P<0.01)$. It is noteworthy that the number of Leydig cells in the $\mathrm{Cl}_{2} \mathrm{MDP}$-lp-injected testes of the animals treated at 20-25 days of age (Fig. 2f) was not significantly different from the number of Leydig cells that were already present in intact rats at the same age at which macrophages were depleted (Fig. 2c).

In the right $\left(\mathrm{Cl}_{2} \mathrm{MDP}\right.$-lp-injected) testes of the animals treated at 5, 10 and 15 days of age, both macrophages and Leydig cells were absent 10 days after treatment, whereas 15 days after treatment, macrophages were present and some Leydig cells were found in the animals that had been injected at 15 days of age. Mast cells were also found in the testicular interstitium 10 and 15 days after treatment, whereas these cells were not found in the left $(\mathrm{NaCl}$-injected) testes.

Compared with their contralateral testes, macrophages and Leydig cells were absent in the $\mathrm{Cl}_{2} \mathrm{MDP}$-lp-injected testes 10 days after treatment (Fig. 3). However, 15 days after treatment significantly fewer macrophages were present $(P<0.01)$ and fewer Leydig cells were also found $(P<0.01)$ in the animals injected at 15 days of age compared with testes treated with $\mathrm{NaCl}$.

Effects of gonadotrophin treatment on the development of Leydig cells in the presence or absence of macrophages (Expt 3)

The left ( $\mathrm{NaCl}$-injected) testes of vehicle-injected or hFSHinjected rats showed normal morphology, with macrophages and Leydig cells in the testicular interstitium (Fig. 4a); in the left testis of rats treated with hCG or with hCG and hFSH, macrophages and Leydig cells were very abundant (Fig. 4c). However, in the right $\left(\mathrm{Cl}_{2} \mathrm{MDP}\right.$-lp-injected) testis of vehicleinjected or hFSH-injected rats, macrophages were absent and Leydig cells were very scarce (Fig. 4 b), and no changes were observed in the right testes after gonadotrophin treatment (Fig. 4d).

Macrophages were absent in the $\mathrm{Cl}_{2} \mathrm{MDP}$-lp-injected testes of all groups (Fig. 5). Treatment with hCG or combined hCG and $\mathrm{hFSH}$ induced a significant $(P<0.01)$ increase in the number of both macrophages and Leydig cells in the $\mathrm{NaCl}$ injected testes, whereas no changes were induced in the right $\left(\mathrm{Cl}_{2} \mathrm{MDP}\right.$-lp-injected) testes, except for the increase in testicular mass. Treatment with FSH did not induce significant changes, except for a slight increase in testicular mass (Fig. 5a).

\section{Discussion}

The prepubertal increase in the number of Leydig cells results from two different mechanisms. First, mesenchymal cell precursors are recruited and differentiate into morphologically recognizable Leydig cells during the third and fourth postnatal weeks, and second, newly formed Leydig cells then proliferate and the final number of Leydig cells is achieved by cell division (Hardy et al., 1989). An equivalent pattern has been reported in adult rats during Leydig cell regeneration after treatment with EDS (Teerds et al., 1990; Myers and Abney, 1991; Gaytan et al., 1992).
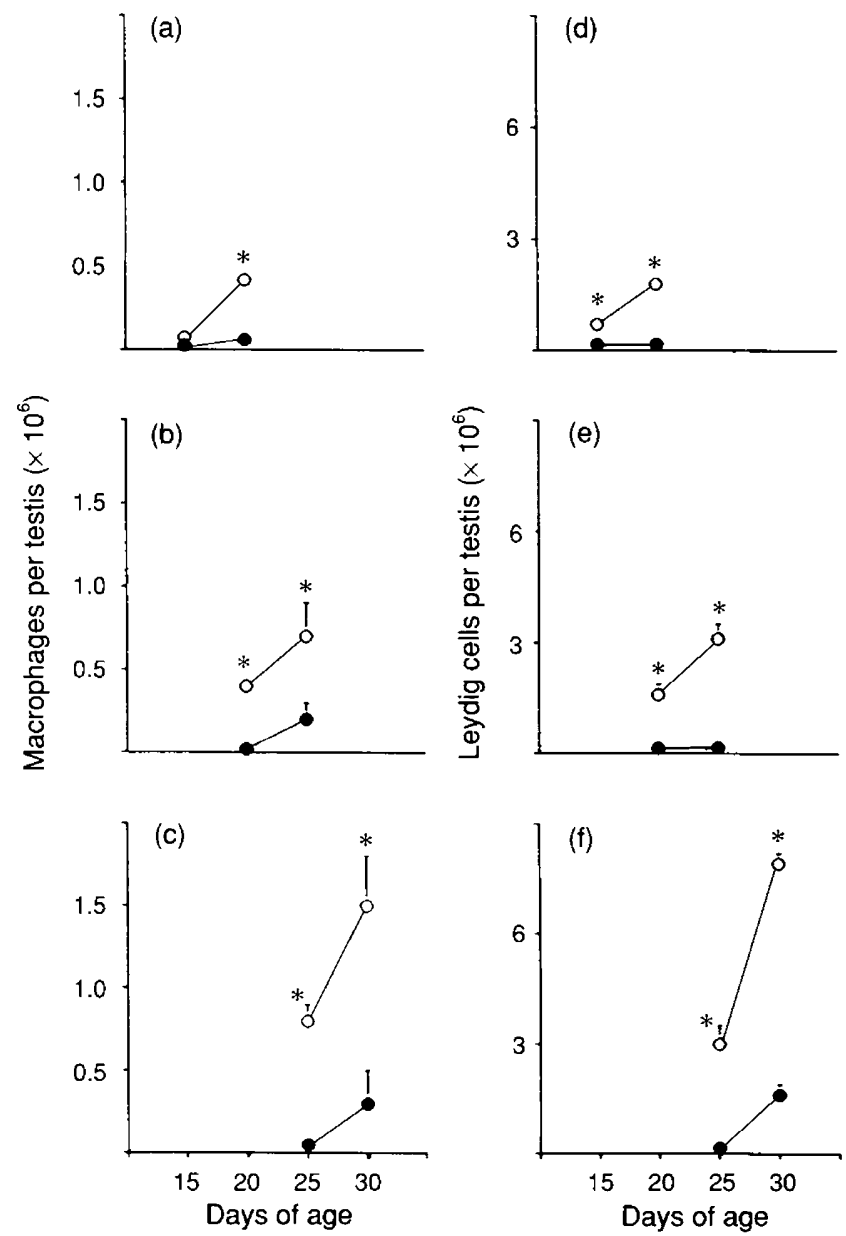

Fig. 3. Recovery of testicular macrophages of rats after depletion at different ages. Number of $(a, b, c)$ macrophages and $(d, e, f)$ Leydig cells in the $\mathrm{NaCl}$-injected testes ( ) and testes injected with dichloromethylene-diphosphonate-containing liposomes $\left(\mathrm{Cl}_{2} \mathrm{MDP}-\mathrm{lp}\right.$ ) (•) of rats treated at (a, d) 5, (b, e) 10 and (c, f) 15 days of age and killed 10 or 15 days after treatment. ${ }^{*} P<0.01$, compared with the contralateral testes (data were analysed using Student's $t$ test for paired data).

In this study, selective depletion of testicular macrophages at different ages inhibited the development of Leydig cells. Depletion of macrophages at 20 or 25 days of age (when few Leydig cells were already present) prevented any further increases in the number of Leydig cells from this time to 35 days of age. Otherwise, in the contralateral, macrophagecontaining testes the number of Leydig cells increased considerably during the same period. This clearly indicates that Leydig cell proliferation does not occur in the absence of macrophages. In the animals in which macrophages were depleted at 5,10 or 15 days of age (when adult-type Leydig cells were absent or very scarce), Leydig cells were nearly absent 10 or 15 days after treatment. At these ages, Hardy et al. (1989) proposed that recruitment of mesenchymal cell precursors was the main mechanism responsible for the increase in the number of Leydig cells (Hardy et al., 1989). The data of this study therefore indicate that at least the last steps of precursor cell differentiation (into morphologically recognizable Leydig cells) were also inhibited in macrophage-depleted testes. In 

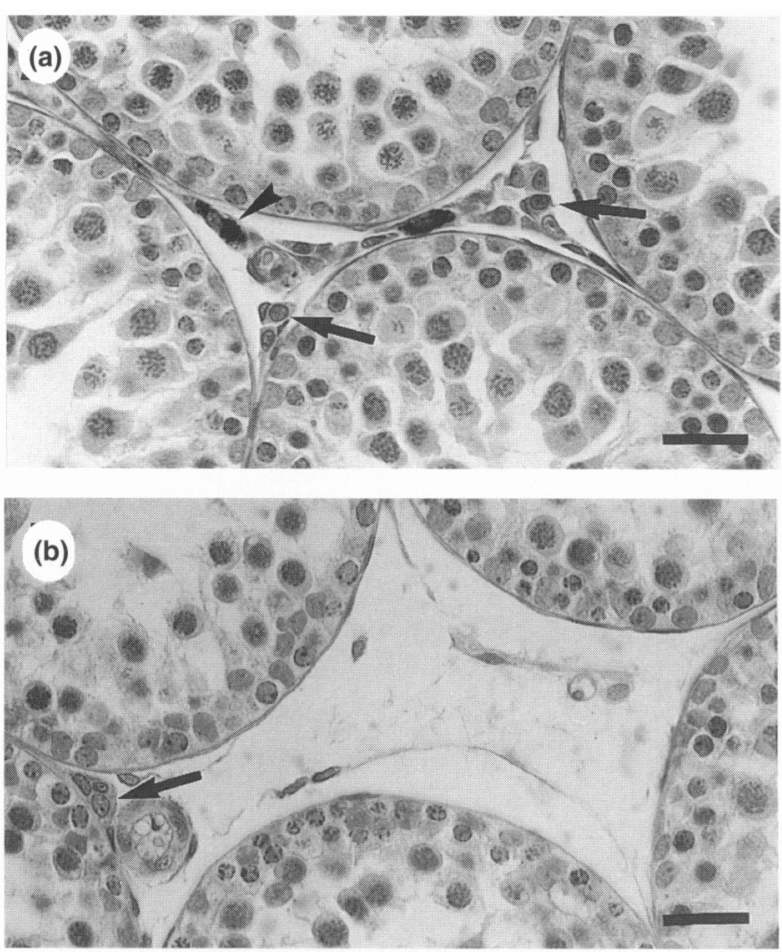
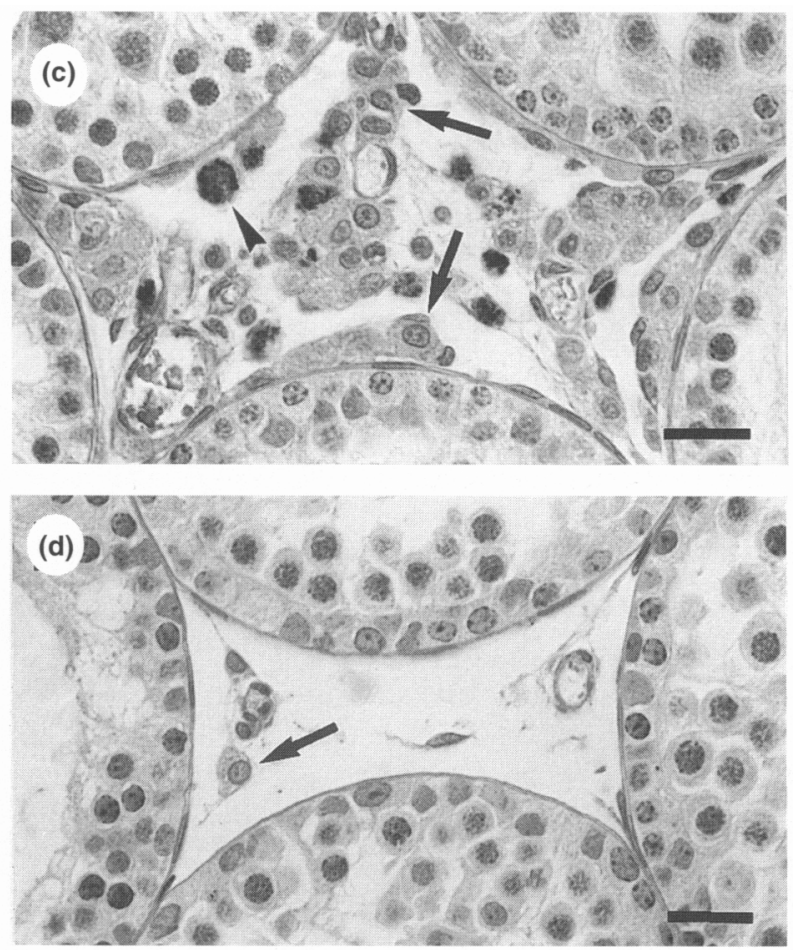

Fig. 4. Representative interstitial areas from $(a, c)$ the left testes of rats treated with $\mathrm{NaCl}$ and $(b, d)$ the right testes of rats treated with dichloromethylene-diphosphonate-containing liposomes $\left(\mathrm{Cl}_{2} \mathrm{MDP}-\mathrm{lp}\right)$ at 18 days of age and 3 days later with (a, b) vehicle or (c, d) 10 iu hCG day ${ }^{-1}$ for 6 days. Sections were stained with $1 \%$ neutral red. Macrophages are indicated by arrowheads and Leydig cells by arrows. Scale bar represents $25 \mu \mathrm{m}$.

young animals, repopulation of the testes with macrophages was faster than in adult rats (Bergh et al., 1983; Gaytan et al., 1994a) and had begun by day 15 after treatment. This repopulation was followed by the appearance of Leydig cells, which were abundant by 35 days of age. This reinforces the notion that Leydig cell development is dependent on macrophages.

Miller et al. (1983) reported that there are specific cell contacts between testicular macrophages and Leydig ceils in adult rats. However, in the maturing testis, the number of macrophages seems not to be enough to stimulate Leydig cell development via direct cell-cell contact. It seems to be more reasonable to speculate that the effects of macrophages are mediated by the secretion of local factors. This contention agrees with previous studies in vitro indicating that macrophage-derived factors such as TGF- $\alpha$ (Rappolee et al, 1988 ) and IL-1 $\beta$ (Xiong et al., 1991) stimulate ${ }^{3} \mathrm{H}$ thymidine incorporation into DNA of immature Leydig cells (Khan et al., 1992a, b).

LH exerts a major stimulatory effect on the development of Leydig cells during testicular maturation (Teerds et al., 1989), and Leydig cells are the only types of testicular cell that express LH and hCG receptors (Segaloff and Ascoli, 1993). It was reported that treatment of hypophysectomized rats with gonadotrophins induces the same pattern of changes in Leydig cells as those observed during pubertal development (Teerds $e f$ al., 1989; Gaytan et al., 1994b). In the study reported here, treatment with hCG caused a sevenfold increase in the number of Leydig cells in the left, macrophage-containing testis, whereas the number of Leydig cells was unchanged in the right, macrophage-depleted testis. These results indicate that macrophage-derived factors are needed for Leydig cell responsiveness to hCG during postnatal development. This contention is also supported by studies in vifro in which IL-I enhanced the ability of hCG to promote DNA synthesis in immature Leydig cells (Khan et al, 1992b).

Pubertal testicular development depends upon the presence of LH (Huhtaniemi et al., 1982; Bellido et al., 1990; Leon et al., 1990). However, the concentration of LH is quite constant during prepubertal development (Döhler and Wuttke, 1974; Odell, 1990); there is therefore no clear correlation between serum LH concentrations and the increasing numbers of Leydig cells. This study provides evidence for the requirement of testicular macrophages for the response of Leydig cells to hCG. Furthermore, macrophages accumulate in the testis during postnatal development (as reported in this study and by Hardy et al., 1989 and Hutson, 1990). Taken together, these data suggest that the postnatal increase in the number of macrophages or their maturation in the testis may be a crucial factor for the enhanced responsiveness of Leydig cells to $\mathrm{LH}$, which then leads to pubertal testicular development.

In addition to LH, FSH has also been found to influence the development of Leydig cells in immature hypophysectomized rats (Kerr and Sharpe, 1985; Teerds et al., 1989). In the study reported here, no clear effects of hFSH were found either in the $\mathrm{NaCl}$-injected or in the $\mathrm{Cl}_{2} \mathrm{MDP}$-lp-injected testes, except for the slight increase in testicular mass. The high concentration of endogenous FSH at this age (Döhler and Wuttke, 1974) probably makes these animals less responsive to exogenous FSH than are hypophysectomized rats. This suggestion 

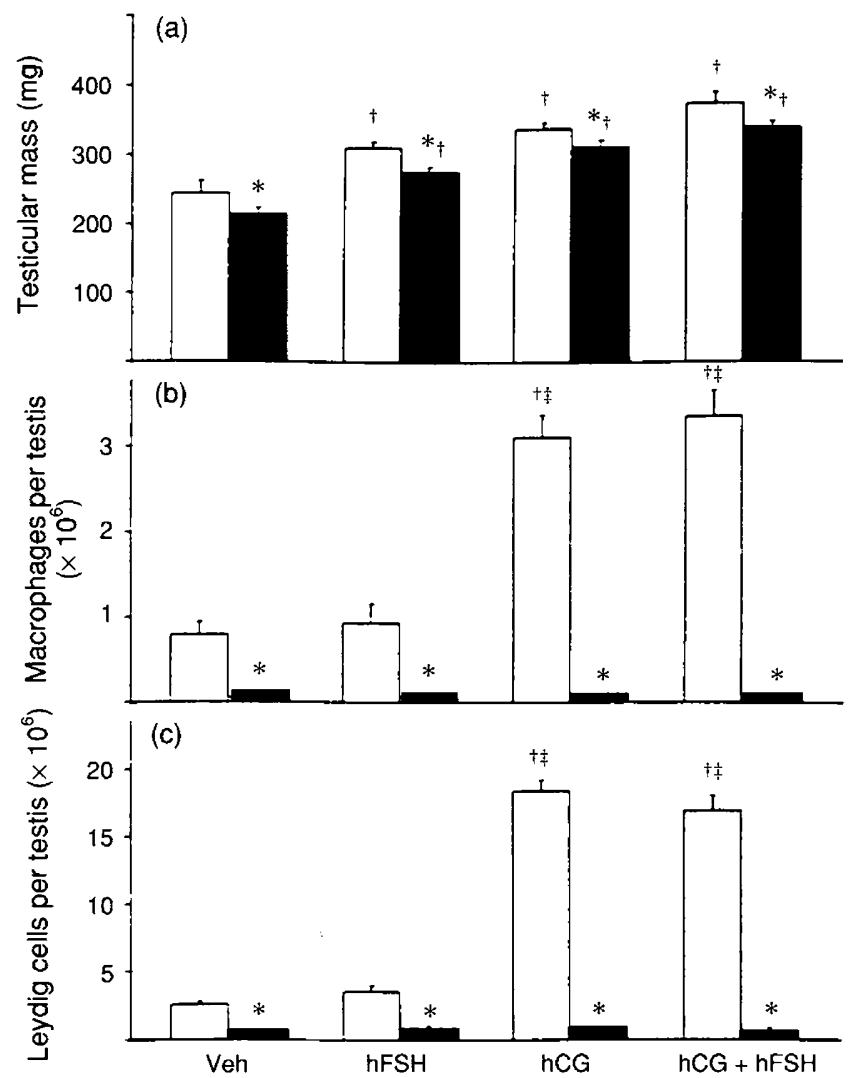

Fig. 5. Response of Leydig cells to gonadotrophin treatment in the presence or absence of testicular macrophages of rats. The effects of gonadotrophins in the left testes treated with $\mathrm{NaCl}(\square)$ and the right testes treated with dichloromethylene-diphosphonate-containing liposomes ( $\mathrm{Cl}_{2}$ MDP-Ip) ( $\left.\boldsymbol{\square}\right)$, and the effects of vehicle (veh), 75 iu in $h$ FSH kg ${ }^{-1}$ bodymass day ${ }^{-1}, 10$ iu hCG per rat day ${ }^{-1}$ or combined hCG and hFSH are shown. ${ }^{*} P<0.01$, compared with the left testes (Student's $t$ test); ${ }^{\dagger} P<0.01$, compared with vehicle-treated rats; ${ }^{\ddagger} P<0.01$, compared with hFSH-treated rats. Data were analysed by ANOVA and Tukey's test.

is in agreement with reports in which FSH treatment did not affect the number of testicular macrophages (Raburn et al., 1991).

In accordance with previous studies (Raburn et al., 1991), hCG treatment increased the number of macrophages in the left ( $\mathrm{NaCl}$-injected) testes. However, no repopulation of the testicular interstitium with macrophages was found in the right $\left(\mathrm{Cl}_{2} \mathrm{MDP}\right.$-lp-injected) testes. Gonadotrophin treatment has been found to have effects on both macrophages and Leydig cells in adult rats (Bergh, 1987; Gaytan et al., 1994b). The effects of gonadotrophin on macrophages are probably mediated by Leydig cells, as LH and hCG receptors are not expressed in macrophages, as is indicated by the lack of hCG binding in the rat testes after destroying Leydig cells with EDS (Jackson et al., 1986). This could explain the lack of macrophage repopulation of the right testes, in which Leydig cells were scarce and did not respond to hormonal treatment. However, the factors controlling macrophage repopulation are unclear.

Despite the lack of response of Leydig cells to gonadotrophin treatment in the testes lacking testicular macrophages, there was a significant increase in the testicular mass. This was probably due to the actions of the androgens released by the contralateral, macrophage-containing testis.

The presence of mast cells in the macrophage-depleted testes of the animals treated on days 10-15 of age was probably due to the absence of Leydig cells during a period after macrophage depletion. Previous studies have shown that mast cells proliferate in the rat testis if Leydig cells are absent (Gaytan et al., 1990), probably in response to Sertoli-cell-derived factors (Tajima et al., 1991). The presence of proliferating mast cells together with the growth of the right testes (under the stimulus of the androgens secreted by the contralateral testes) indicate that the inhibition of Leydig cell proliferation in $\mathrm{Cl}_{2} \mathrm{MDP}$-lpinjected testes was not due to nonspecific environmental alterations induced by the intratesticular treatment.

Several growth factors are implicated in the proliferation and differentiation of most cell types (Deuel, 1987). From the results of this study, it can be concluded that macrophagederived factors are needed for Leydig cells to undergo proliferation and differentiation during postnatal development.

The authors thank J. F. Tresguerres for the gift of hFSH, and J. Molina and E. Tarradas for their technical assistance.

\section{References}

Bellido C, Pinilla L, Aguilar R, Gaytan F and Aguilar E (1990) Possible role of changes in post-natal gonadotrophin concentrations on permanent impairment of the reproductive system in neonatally oestrogenized male rats Journal of Reproduction and Fertility 90 369-374

Bergendahl M, Perheentupa A and Huhtaniemi I (1991) Starvation-induced suppression of pituitary-testicular function in rats is reversed by pulsatile gonadotropin-releasing hormone substitution Biology of Reproduction $\mathbf{4 4}$ 413-419

Bergh A (1981) Morphological signs of a direct effect of experimental cryptorchidism on the Sertoli cells in rats irradiated as fetuses Biology of Reproduction 24 145-152

Bergh A (1987) Treatment with HCG increases the size of Leydig cells and testicular macrophages in unilaterally cryptorchid rats Intemational journal of Andrology $10765-772$

Bergh A, Damber JE and van Rooijen N (1993) Liposome-mediated macrophage depletion: an experimental approach to study the role of testicular macrophages in the rat Journal of Endocrinology $136407-413$

Deuel TF (1987) Polypeptide growth factors: roles in normal and abnormal cell growth Annual Review of Cell Biology 3 443-492

Döhler KD and Wuttke W (1974) Serum LH, FSH, prolactin and progesterone from birth to puberty in female and male rats Endocrinology 94 1003-1008

Elias $\mathbf{H}$ and Hyde DM (1980) An elementary introduction to sterology (quantitative microscopy) American Joumal of Anatomy 159 411-446

Gaytan F, Bellido C, Aceitero J, Aguilar E and Sanchez-Criado JE (1990) Leydig cell involvement in the paracrine regulation of mast cells in the testicular interstitium of the rat Biology of Reproduction 43 665-67I

Gaytan F, Aceitero J, Lucena C, Aguilar E, Pinilla L, Garnelo P and Bellido C (1992) Simultaneous proliferation and differentiation of mast cell and Leydig cell in the rat testis. Are common regulatory factors involved? Journal of Aridrology 13 387-397

Gaytan F, Bellido C, Morales C, Reymundo C, Aguilar E and van Rooijen N (1994a) Selective depletion of testicular macrophages and prevention of Leydig cell repopulation after treatment with ethylene dimethane sulphonate (EDS) in rats Joumal of Reproduction and Fertility 101 175-182

Gaytan F, Bellido C, Romero JL, Morales C, Reymundo C and Aguilar E (1994b) Decreased number and size and the defective function of testicular macrophages in long-term hypophysectomized rats are reversed by treatment with human gonadotrophins Journal of Endocrinology 140 399-407

Hardy MP, Zirkin BR and Ewing LL (1989) Kinetic studies on the development of the adult population of Leydig cells in testes of the pubertal rat Endocrinology $\mathbf{1 2 4} 762-770$ 
Huhtaniemi IT, Nozu K, Dwight WW, Dufau ML and Catt KJ (1982) Acquisition of regulatory mechanisms for gonadotropin receptors and steroidogenesis in the maturing rat testis Endocrinology 111 1711-1720

Hutson JC (1990) Changes in the concentration and size of testicular macrophages during development Biology of Reproduction 43 885-890

Jackson MC, Jackson H, Shanks JH, Dixon JS and Lendon RG (1986) Study using in vivo binding of ${ }^{225}$ I-labelled HCG, light and electron microscopy of the repopulation of rat Leydig cells after destruction due to administration of ethylene-1,2 dimethanesulphonate Journal of Reproduction and Fertitity $\mathbf{7 6}$ $1-10$

Kerr JB and Knell CM (1988) The fate of fetal Leydig cells during the development of the fetal and postnatal rat testis Development 103 535-544

Kerr JB and Sharpe RM (1985) Follicle-stimulating hormone induction of Leydig cell maturation Endocrinology 116 2592-2604

Khan SA, Teerds K and Dorrington JH (1992a) Growth factor requirements for DNA synthesis by Leydig cells from the immature rat Biology of Reproduction 46 335-341

Khan SA, Khan SI and Dorrington JH (1992b) Interleukin-1 stimulates deoxyribonucleic acid synthesis in immature rat Leydig cells in vitro Endocrinology 131 1853-1856

Leon MD, Calvo JC, Charreau EH and Chemes HE (1990) Developmental changes in testicular interstitial cell populations, $\mathrm{LH}$ receptors and the response to hCG in the rat International Journal of Andrology $13 \quad 110-122$

Loud AV, Anversa P, Giacomelli F and Wiener J (1978) Absolute morphometric study of myocardial hypertrophy in experimental hypertension. I. Determination of myocyte size Laboratory Investizations 38 586-596

Miller SC, Bowman BM and Rowland H (1983) Structure, cytochemistry, endocytic activity, and immunoglobulin $(\mathrm{Fc})$ receptors of rat testicular interstitial-tissue macrophages American Journal of Anatomy 168 I-13

Moore A and Morris FD (1993) The involvement of insulin-like growth factor-I in local control of steroidogenesis and DNA synthesis of Leydig and non-Leydig cells in the rat testicular interstitium Journal of Endocrinology $\mathbf{1 3 8}$ 107-114

Moore C and Hutson JC (1994) Physiological relevance of tumor necrosis factor in mediating macrophage-Leydig cell interactions Endocrinology 134 63-69

Moradian AD, Morley JE and Korenman SG (1987) Biological actions of androgens Endocrine Reviews 8 1-28

Myers RB and Abney TO (1991) Interstitial cell proliferation in the testis of the ethylene dimethane sulfonate-treated rat Steroids 56 91-96

Odell WD (1990) Sexual maturation in the rat. In Control of the Onset of Puterty, pp 183-230 Eds MM Grumbach, PC Sizonenko and ML Aubert. Williams \& Wilkins, Baltimore
Raburn DJ, Coquelin A and Hutson JC (1991) Human chorionic gonadotropin increases the concentration of macrophages in neonatal rat testis Biology of Reproduction 45 172-177

Rappolee DA, Mark D, Banda MJ and Werb Z (1988) Wound macrophages express TGF- $\alpha$ and other growth factors in vivo: analysis by mRNA phenotyping Science 241 708-712

Segaloff DL and Ascoli M (1993) The lutropin/chorionic gonadotropin receptor 4 years later Endocrine Reviews 14 324-347

Skinner MK (1991) Cell-cell interactions in the testis Endocrine Reviews 12 $45-77$

Spiteri-Grech J and Nieschlag E (1993) Paracrine factors relevant to the regulation of spermatogenesis - a review journal of Reproduction and Fertility $981-14$

Sun XR and Risbridger GP (1994) Site of macrophage inhibition of luteinizing hormone-stimulated testosterone production by purified Leydig cells Biology of Reproduction 50 363-367

Tajima Y, Onoue H, Kitamura $Y$ and Nishimune $Y$ (1991) Biologically active kit ligand growth factor is produced by mouse Sertoli cells and is defective in $\mathrm{Sl}^{\mathrm{d}}$ mutant mice Development 113 1031-1035

Teerds KJ, Closset J, Rommerts FFG, de Rooij DG, Stocco DM, Colenbrander B, Wensing CJG and Hennen G (1989) Effects of pure FSH and LH preparation on the number and function of Leydig cells in immature hypophysectomized rats Journal of Endocrinology 120 97-106

Teerds KJ, de Rooij DG, Rommerts FFG and Wensing CJG (1990) Development of a new Leydig cell population after the destruction of existing Leydig cells by ethylene dimethane sulphonate in rats: an autoradiographic study Journal of Endocrinology 126 229-236

van Rooijen N (1989) The liposome-mediated macrophage suicide technique Journal of Immunological Methods 124 1-6

Xiong $Y$ and Hales DB (1993) The role of tumor necrosis factor- $\alpha$ in the regulation of mouse Leydig cell steroidogenesis Endocrinology 132 $2438-2444$

Xiong Y, Okuno WM and Hales DB (1991) Testicular interstitial macrophages (TIMS) express interleukin-1 mRNA: possible paracrine regulation of P450-17 alpha gene expression in Leydig cells Program of the 73rd Annual Meeting of The Endocrine Society. Washington DC, 1981 p. 382 (Abstract)

Yee JB and Hutson JC (1985) Effects of testicular macrophage-conditioned medium on Leydig cells in culture Endocrinology 116 2682-2684 